January 1989

\title{
Seasonal Affective Disorder: SAD or Fad?
}

\author{
J. Thomas Pichot, MD \\ Eisenhower Army Medical Center, Fort Gordon Georgia \\ Peter S. Jensen, MD \\ Walter Reed Institute of Research, Washington DC
}

Follow this and additional works at: https://jdc.jefferson.edu/jeffjpsychiatry

Part of the Psychiatry Commons

Let us know how access to this document benefits you

\section{Recommended Citation}

Pichot, MD, J. Thomas and Jensen, MD, Peter S. (1989) "Seasonal Affective Disorder: SAD or Fad?," Jefferson Journal of Psychiatry. Vol. 7 : Iss. 1 , Article 7.

DOI: https://doi.org/10.29046/JJP.007.1.004

Available at: https://jdc.jefferson.edu/jeffjpsychiatry/vol7/iss1/7

This Article is brought to you for free and open access by the Jefferson Digital Commons. The Jefferson Digital Commons is a service of Thomas Jefferson University's Center for Teaching and Learning (CTL). The Commons is a showcase for Jefferson books and journals, peer-reviewed scholarly publications, unique historical collections from the University archives, and teaching tools. The Jefferson Digital Commons allows researchers and interested readers anywhere in the world to learn about and keep up to date with Jefferson scholarship. This article has been accepted for inclusion in Jefferson Journal of Psychiatry by an authorized administrator of the Jefferson Digital Commons. For more information, please contact: JeffersonDigitalCommons@jefferson.edu. 


\title{
Seasonal Affective Disorder: SAD or Fad?
}

\author{
J. Thomas Pichot, M.D. \\ Peter S. Jensen, M.D.
}

Seasonal affective disorder (SAD) and phototherapy have recently been the subject of a great deal of interest in the psychiatric literature. First described in 1984 (1), SAD is now defined as "a cyclic illness characterized by recurrent episodes of fall/winter depression alternating with periods of spring/summer euthymia (normal mood) or hypomania (mild elation and behavioral activation)" (2). Recent findings indicate that there may be at least two additional patterns of seasonal depressions, one characterized by annual summer depressions with euthymic, hypomanic or manic symptoms in the winter, and the other characterized by depressive episodes occurring in both winter and summer (3-6).

As defined by Rosenthal et al. (3), SAD diagnostic criteria include:

1) a history of at least one major depressive episode, according to RDC (7) criteria;

2) regularly occurring fall-winter depressions (at least two occurring during consecutive winters) alternating with nondepressed periods during spring and summer;

3) no other major psychiatric disorders; and,

4) no psychosocial variables accounting for the regular changes in mood.

$\mathrm{SAD}$ has gained increased acceptance with the inclusion of "seasonal pattern" criteria for a number of different diagnoses within the Mood Disorder section of DSM III-R (8).

Recently a number of reports of additional "seasonal" diagnostic entities have appeared in the scientific literature, including, "reverse seasonal affective disorder" (3), "seasonal affective disorder in children and adolescents" (9), "seasonal premenstrual syndrome" (10), seasonal battering of women (11) and a hypothesized seasonal obesity disorder (12). Furthermore, the lay press has reported extensively on SAD and phototherapy (13-19), with phototherapy currently being touted as potentially beneficial for depression, multiple sclerosis, AIDS, premenstrual syndrome, school absenteeism, low work productivity, poor morale, jet lag, and dental cavities (13-20).

While others have written to express concern about the validity of these diagnoses and there proposed etiologies (21-23), the validity of the diagnosis of $\mathrm{SAD}$ is the focus of this paper.

\section{LITERATURE SUPPORT FOR SAD}

Although numerous papers have been published over the years that support the existence of seasonal differences in psychiatric disorders (24-39), 
many of these early papers do not seem readily applicable to support current notions of the entity of SAD. Although, Rosenthal et al. briefly allude to the numerous discrepancies in these early studies (40), Christensen et al. in the "Myths of Mid-Winter Depression," present a detailed literature review of the conflicting nature of the empirical data that relates to seasonal peaks of psychiatric disorders (41). On closer review many of these seasonal study populations do not appear to relate to the current populations being described as having the SAD diagnosis. For example, the early research was done almost exclusively with psychiatric inpatients and with few exceptions (42), SAD is described as a mild disorder found primarily in outpatient populations (13,43-45). Many of the early studies did not differentiate the specific "seasonal" diagnoses, or if diagnoses were provided, they did not discuss the specific symptomatology. In addition, although not specifically stated, one must assume from the current clinical descriptions of SAD that most patients do not display suicidal thoughts or suicidal behavior, therefore, excluding many of the subject populations reported on in the papers on seasonality of suicides.

A related issue is the lack of current epidemiologic evidence for SAD and the absence of literature support for determining its reliability, validity or prevalence as a psychiatric diagnosis. The patient population upon which the SAD diagnosis was developed was a partly self-selected research population at NIMH, which was included in what appears to be a non-controlled phototherapy trial (1). Unfortunately, the majority of the follow-up studies, by NIMH and other groups, have used this same method of subject selection to develop their study populations, to test the effects of phototherapy and to establish their demographic data. An exception to this approach was a recent comparison of seasonal and nonseasonal affective disorders (46). This study used a psychiatry clinic population as its source of subjects, did not incorporate a phototherapy protocol, and used a control population to test their hypothesis. They reported a "prevalence of seasonal depression" of $38 \%$ in their study population (46), whereas the most frequently quoted prevalence estimate for SAD has been "about 4-5\% of manic-depressive patients" (47). Unfortunately, Garvey et al. use their own idiosyncratic criteria to diagnosis SAD (46). In fact, this type of diagnostic variance is a common problem throughout the SAD literature. The significance of this variability in describing psychiatric syndromes has been discussed by Spitzer (49). He stated that "criterion variance" occurs when there are differences in the criteria that are used to make a certain diagnosis and this is one of the major sources of difficulty with reliability in psychiatric diagnoses.

\section{POOR RELIABILITY DUE TO CRITERION VARIANCE}

Development of diagnostic criteria would provide a means to verify reliability of $\mathrm{SAD}$ as a diagnosis and possibly establish its descriptive validity. However, while most researchers have attempted to describe the diagnosis of SAD based on the Research Diagnostic Criteria (RDC) for major depression (7), 
there is a recurring problem with various authors changing the SAD criteria they report in their individual studies. While Rosenthal et al. have reported that other researchers have used similar criteria (3), a review shows that the current SAD criteria differ significantly from those initially presented in 1984 (1) and those presented by other groups $(2,47,48)$. Sometimes the changes are quite extensive, such as, diagnosing SAD without a major affective diagnosis as a criteria (47), leaving out criteria pertaining to psychosocial influences (1), or not ruling out other psychiatric disorders (48). Therefore, failure to specifically define how these individuals are being diagnosed could decrease the reliability of SAD. Perhaps this accounts for Yerevanian et al. reporting that SAD patients usually have unipolar disorder (50), Rosenthal et al. reporting that SAD patients usually have bipolar disorder $(1,3)$, and Wirz-Justice et al. reporting that SAD patients usually give a history consistent with bipolar disorder, but actually fail to show any evidence of mania or hypomania on longitudinal follow-up into the spring/summer (47).

\section{ETIOLOGIC HYPOTHESES}

Rosenthal and Fishman (51) recently reviewed current theories of the reported antidepressant effect of light on SAD patients and discussed four:

THE MELATONIN THEORY: Melatonin is secreted in a circadian pattern with nocturnal release from the pineal gland in response to environmental light input to the retinas. The pathway of information flow is reported as; light input to the retinas is passed along the retino-hypothalamic tract to the suprachiasmatic nuclei of the hypothalamus, which in turn stimulates the specific pattern of melatonin release from the pineal gland. In SAD it is postulated that "the symptoms of SAD are due to an abnormality in melatonin secretion or, perhaps, an abnormal brain response to melatonin" (51). While not being totally excluded, this theory seems less plausible now that report data indicates that melatonin suppression is not necessary to demonstrate beneficial effects of light treatment (48).

THE PHASE-SHIFT HYPOTHESIS: A theory discussed by numerous authors (51-56), who postulate that "light corrects an abnormality of circadian phase either relative to real clock time or internally (between different circadian rhythms)" (51). These authors have also speculated that exposure to light in the morning brings the SAD patient's rhythms back to normal, thus stabilizing their mood. Conversely they suggest that phototherapy in the evenings should delay circadian rhythms, thus exacerbating the patient's symptoms. The most important arguments against this theory are the more recent reports that the time of day of phototherapy application does not alter the antidepressant effect of phototherapy $(9,48,57)$.

THE DIRECT PHOTO-CHEMICAL HYPOTHESIS: This is a general theory that postulates an abnormality existing in the brain, perhaps in the hypothalamus, that is probably genetic and which produces the symptoms of 
SAD in the absence of sufficient light. Phototherapy functions by reversing this brain deficiency (51).

THE PLACEBO THEORY: A major concern with all of the SAD literature lies in the difficulty of controlling for placebo and positive expectancy effects. This is particularly important because most of the literature that bears on the biologic theories seems to argue by inference that response to phototherapy treatment constitutes reasonable evidence of the validity of the SAD diagnosis $(1-5,47,52)$. Further, a number of SAD papers do not consider the placebo effect at all $(3-5,42,55)$, while papers that do, provide a one-sided argument against it $(1-2,44-45,47-48,51,53,58)$.

Proponents of SAD and light treatment accept that the consistent two- to four-day time lag for improvement with phototherapy and the likelihood of relapse occurring over a similar time span when the lights are withdrawn mitigate against the placebo hypothesis. Also, SAD researchers report that the beneficial effects of phototherapy persist throughout the treatment course and reliably return with subsequent treatments during relapses. Furthermore, a fair degree of consistent findings in phototherapy responses from year to year and between different investigative groups $(1,47,59)$ has been claimed, as well as a dose-response relationship. To bolster arguments against the placebo theory, proponents also cite the evidence of a circadian rhythm in response sensitivity to treatment (i.e. "some studies have shown a greater efficacy of light treatment in the morning than in the evening”) (61-62). Additionally, SAD proponents invoke the notions about light's multiple biological effects (61-68) and the superiority of light therapy compared to sham light control treatments $(1,47,53,69,70)$ as evidence to refute the placebo effect.

However, accumulating evidence seems to refute a number of these arguments: In regard to the reported consistent time lag until symptom relapse when lights are withdrawn, at least one group reports that symptom relapse is not consistent and may occur within one day of the withdrawal of lights or not occur at all (47). Also, recent data suggests that a circadian sensitivity to response to timing of phototherapy is not present, as the timing of the phototherapy is not critical for producing the antidepressant effect (i.e. applications at various times throughout the day and evening have resulted in beneficial effects) $(48,57,69-$ $70)$.

The theory behind dim (250-300 lux) light as a control versus bright $(2,500$ lux $)$ light as the active treatment was initially based on the finding that at 500 lux, light suppresses production of melatonin in normal volunteers (61). However, a subsequent study demonstrated that the suppression of melatonin is not necessary for phototherapy to produce its antidepressant effect in SAD patients (48). This finding casts doubt not only on the melatonin hypothesis, but also on the use of dim light as a "nonactive" control and bright light as an "active" treatment. Wehr et al. have reported that dim "control" lights have repeatedly not shown significant antidepressant effects (48) and that other 
studies have confirmed these findings $(47,59)$. However, a review of the other studies they reference reveals that Wirz-Justice et al., reports antidepressant effects with dim light, at levels as low as 250 lux, in $83 \%$ of their SAD population $(47,71)$. One of the other papers, by Hellekson et al., was a non-controlled treatment trial of six SAD patients that used only bright light (2500 lux) (59). Furthermore, Wirz-Justice et al. (47) note that 30 to $40 \%$ of SAD patients in previous phototherapy trials have responded to dim light $(1,57,58)$. These authors speculate that with the small number of subjects in all of these SAD studies, such differences in response may be related to the selection criteria (47). Doubts are further increased by reports that, in addition to less light intensity, antidepressant responses are seen with less time of exposure to phototherapy $(9,47)$.

SAD advocates note that "patients become depressed in a regular and predictable way" (3), yet almost $40 \%$ of Rosenthal et al.'s initial group of SAD patients failed to develop any evidence of depression when followed during the fall/winter of 1984 (1). Further Rosenthal et al. report that $>90 \%$ of SAD patients have a bipolar disorder (3), yet two other groups have reported that none of their SAD patients displayed evidence of mania or hypomania on follow up $(47,50)$. Furthermore, while "winter depression" is the term that is used with the diagnosis, the actual onset of the reported depressions can occur anytime between July and January (5).

Additional arguments for light being an "active" agent, and not a placebo effect were presented by Wirz-Justice et al. (47). The authors stated that placebo effects are more evident in mild or neurotic depressions and report that their SAD patients were severely depressed. This argument is problematic for two reasons: First, there is little empirical evidence to support this assertion because placebo reactions are commonly demonstrated in normal, neurotic and psychotic individuals (62). Second, as stated before most SAD patients are reported to have "mild" depressions (1-2,43-45). Further, they argue that the "use of lights under self-selected conditions led to repeated improvement in the same individual." While we would agree this probably suggests the individual is deriving some type of benefit from phototherapy, it is not clear if it serves to differentiate "active" from "placebo" origins of that benefit, particularly in light of the reports of conditioned placebo effects (72-73). Lastly, they assert that "relapse after withdrawal is considered a criterion for an active agent." The authors did not provide a reference for this statement, however there are reports that individuals have displayed several years of chronic dependence with withdrawal symptoms on placebo alone (74). Further, drug withdrawal symptoms may occur as a psychologically conditioned responses, rather than as biologically induced symptoms (72-73).

The placebo effect has been the subject of extensive research and there is little doubt that it occurs in both experimental and clinical studies (75). Some of the findings about placebo responses that are applicable to the current discus- 
sion of SAD include: A positive therapeutic response of almost $100 \%$ has been reported with placebo alone (72-75), this could account for the $80 \%$ positive response rate most frequently reported for phototherapy (3). In addition, the most frequently cited symptoms associated with the placebo reaction are “depression, anxiety and emotionality" (75), whereas Rosenthal et al. report the three affects associated with SAD are "sadness, anxiety and irritability." Nausea, headaches, and nervousness are side effects that are frequently seen with placebos (75). Wirz-Justice et al. report phototherapy side effects consist of nausea, headaches, “hypomanic activation," and/or irritability (42).

Experimenter bias explains why uncontrolled studies report success more frequently than controlled studies (75). While it has been demonstrated that the transfer of researcher bias to patients can occur subtlety (75), in the phototherapy trials written presentation of the researchers' SAD theories and past "successful" use of light treatments are used as pre-conditions for subject selection $(1,9,44,45,49,59)$.

\section{DISCUSSION}

We have been unable to find any clinical, demographic, family history, laboratory study, or controlled light therapy research that has validated SAD as a distinct syndrome. Yet despite this lack of support we now see a flurry of additional "seasonal" diagnostic entities appearing in the scientific literature $(3,9-12,20)$ and the lay press (13-19). One must question whether seasonal variation in mood is a characteristic found in the general population, including psychiatric patients generally, or if there is actually a distinct subgroup with extreme seasonal differences in psychiatric symptoms.

Furthermore, if SAD represents some type of specific biologic mechanism, similar to hibernation in animals (3), why is there so much variability in the onset, presentation, and response to treatment? These differences occur within individual patients and when comparing different SAD patients.

As recently pointed out by Winokur et al., "making up new sets of diagnostic criteria in American psychiatry has become a cottage industry with little attempt at quality control" (76). The history of psychiatry and medicine is marked with clinicians and researchers alike embracing new disorders and uncontrolled treatments, which for a while, seem to provide dramatic progress. Only after further clinical experience and judicious application of the scientific method, do these breakthroughs assume a more modest position in the understanding of psychiatric disorders and their treatments. Although face validity may be the first step toward identifying a psychiatric disorder (77), we must be able to establish more powerful types of diagnostic validity, such as descriptive and predictive validity. Only if such conditions can be met can we justify presenting SAD as a distinct behavioral syndrome, rather than a random collection of clinical features commonly seen in individuals with other types of mental disorders and in individuals without mental disorders. 


\section{REFERENCES}

1. Rosenthal NE, Sack DA, Gillin JC, et al: Seasonal affective disorder- A description of the syndrome and preliminary findings with light therapy. Arch Gen Psychiatry $41: 72-80,1984$

2. Jacobsen FM, Wehr TA, Sack DA, et al: Seasonal affective disorder: A review of the syndrome and its public health implications. Am J Public Health 77:57-60, 1987

3. Rosenthal NE, Wehr TA: Seasonal Affective Disorder. Psychiatric Annals 17:670674,1987

4. Wehr TA, Sack DA, Rosenthal NE: Seasonal affective disorder with summer depression and winter hypomania. Am J Psychiatry 144:1602-1603, 1987

5. Wehr TA: Causes and treatment of seasonal mood disorders. Symposia Presentation, APA annual meeting, Montreal, Canada, 1988

6. Gupta R: Alternative patterns of seasonal affective disorder: Three case reports from North India. Am J Psychiatry 145:515-516, 1988

7. Spitzer RL, Endicott J, Robins E: Research diagnostic criteria- rationale and reliability. Arch Gen Psych 35:773-782, 1978

8. American Psychiatric Association: Diagnostic and Statistical Manual of Mental Disorders, Third Edition, Revised. Washington, DC, American Psychiatric Association, 1987

9. Rosenthal NE, Carpenter CJ, James SP, et al: Seasonal affective disorder in children and adolescents. Am J Psychiatry 143:356-358, 1986

10. Parry BL, Rosenthal NE, Tamarkin L, et al: Treatment of a patient with seasonal premenstrual syndrome. Am J Psychiatry 144:762-766, 1987

11. Michael RP, Zumpe D: An annual rhythm in the battering of women. Am J Psychiatry 143:637-640, 1986

12. Rosenthal NE, Genhart M, Jacobsen FM, et al: Disturbances of appetite and weight regulation in Seasonal affective disorder. Ann NY Acad Sci 499:216-230, 1987

13. Costigan K: Cabin fever. Forbes May 1985;234, 238

14. Brody J: Sunlight important to health in twilight winter months. Augusta Herald 29 NOV 1984

15. Ponte L: Staying happy in cold, dark winter. Reader's Digest Jan 86-89, 1984

16. Dullea G: Shedding light on dark-day blues. New York Times 19 DEC C1,C12, 1985

17. Toufexis A: Dark days, darker spirits: Get the blahs every winter? You may be a SAD victim. Time 11 Jan 66, 1988

18. Springere I: Shedding light on productivity. N.H. Business Review 21 APR 25, 1988

19. Spraque T: New lighting reduces absenteeism in local classrooms. Brattleboro Reformer, Brattleboro, VT: 28 Nov 1987

20. London WP: Full-spectrum classroom light and sickness in pupils. Lancet 2:12041205,1987

21. Severino SK: Defining late luteal dysphoric disorder (letter). Am J Psychiatry $145: 132,1988$

22. Ronat J: Seasonal changes in aggressivity. Am J Psychiatry 144:824, 1987

23. Weale R: Light on seasonal affective disorder? British Medical Journal 296:359-360, 1988 
24. Hare EH: Seasonal variations in psychiatric illness. Trends in Neurosciences 3:295298, 1980

25. Cerbus G, Travis RJ: Seasonal variation of personality of college students as measured by the MMPI. Psychological Reports 33:665-666, 1973

26. Eastwood MR, Stiasny S: Psychiatric disorder, hospital admission, and season. Arch Gen Psychiatry 35:769-771, 1978

27. Hauck PA: Seasonal changes in admission rates of a state hospital. J Clinical Psychol 13:305-309, 1957

28. Chambers W: Seasonal variation in military neuropsychiatric admissions. J Nerv Ment Dis 123:480-483, 1956

29. Zung WW, Green RL: Seasonal variation of suicide and depression. Arch Gen Psychiatry 30:89-91, 1974

30. Parker G, Walter S: Seasonal variation in depressive disorders and suicidal deaths in New South Wales. Brit J Psychiatry 140:626-632, 1982

31. Myers DH, Davies P: The seasonal incidence of mania and its relationship to climatic variables. Psychological Medicine 8:433-440, 1978

32. Cerbus G: Seasonal variation in some mental health statistics: Suicides, homicides, psychiatric admissions, and institutional placement of the retarded. J Clin Psychology 26:61-63, 1970

33. Stewart BC, Wildman RW: Climatic conditions and southern state hospital admission rates. J Clinical Psychol 23:397-98, 1967

34. James R, Griffin A: Seasonal admission rates in Texas mental hospitals. J Clinical Psychol 24:190, 1968

35. Hare EH, Walter SD: Seasonal variation in admissions of psychiatric patients and its relation to seasonal variation in their births. $J$ of Epidem and Community Health $32: 47-52,1978$

36. Lester D: Seasonal variation in suicidal deaths. British J Psychiatry 118:627-628, 1971

37. Eastwood MR, Peacocke J: Seasonal patterns of suicide, depression and electroconvulsive therapy. British J Psychiatry 129:472-475, 1976

38. Symonds RL, Williams P: Seasonal Variation in the incidence of mania. Brit J Psychiatry 129:45-48, 1976

39. Walter SD: Seasonality of mania: a reappraisal. Brit J Psychiatry 131:345-350, 1977

40. Rosenthal NE, Sack DA, Wehr TA: Seasonal variation in affective disorders, in Circadian Rhythms in Psychiatry. Edited by Wehr TA, Goodwin FK. Pacific Grove, CA, Boxwood Press, 1983

41. Christensen R, Dowrick PW: Myths of mid-winter depression. Community Mental Health Journal 19:177-186, 1983

42. Bick PA: Seasonal major affective disorder. Am J Psychiatry 143:90-91, 1986

43. Lewy AJ, Kern HA, Rosenthal NE, et al: Bright artificial light treatment of a manic depressive patient with a seasonal mood cycle. Am J Psychiatry 139:1496-1497, 1982

44. Wehr TA, Skwerer RG, Jacobsen FM, et al: Eye versus skin phototherapy of seasonal affective disorder. Am J Psychiatry 144:753-755, 1987

45. Rosenthal NE, Jacobsen, Sack DA, et al: Atenolol in seasonal affective disorder: A test of the melatonin hypothesis. Am J Psychiatry 145:52-56, 1988 
46. Garvey MJ, Wesner R, Godes M: Comparison of seasonal and nonseasonal affective disorders. Am J Psychiatry 145:100-102, 1988

47. Wirz-Justice A, Bucheli C, Graw P, et al: Light treatment of seasonal affective disorder in Switzerland. Acta Psychiatr Scand 74:193-204, 1986

48. Wehr TA, Jacobsen FM, Sack DA, et al: Phototherapy of seasonal affective disorders- Time of day and suppression of melatonin are not critical for antidepressant effects. Arch Gen Psych 43:870-875, 1986

49. Spitzer RL, Williams JB: Classification of mental disorders and DSM-III, in Comprehensive Textbook of Psychiatry III. Edited by Kaplan HI, Freedman AM, Sadock BJ, Baltimore, Williams and Wilkins, 1980

50. Yerevanian BI, Anderson JL, Grota LJ, et al: Effects of bright incandescent light on seasonal and nonseasonal major depressive disorder. Psychiatry Research 18:355364,1986

51. Rosenthal N, Fishman H: Advances in treating depression. The Psychiatric Times, 5:32-34, 1988

52. Kripke DF, Mullaney DJ, Atkinson M, et al: Circadian rhythm disorders in manicdepressives. Biological Psychiatry 13:335-351, 1978

53. Kripke DF, Risch SC, Janowsky D: Bright white light alleviates depression. Psychiatry Research 10:105-112, 1983

54. Kripke DF: Phase-advance theories for affective illnesses, in Circadian Rhythms in Psychiatry. Edited by Wehr TA, Goodwin FK. Pacific Grove, CA, Boxwood Press, 1983

55. Kripke DF: Therapeutic effects of bright light in depressed patients. Annals NY Acad Sci 453:27 1-281, 1985

56. Johnson $\mathrm{CH}$, Hastings JW: The elusive mechanisms of the circadian clock. American Scientist 74:29-36, 1986

57. James SP, Wehr TA, Sack DA, et al: Treatment of seasonal affective disorder with light in the Evening. British Journal of Psychiatry 147:424-428, 1985

58. Rosenthal NE, Sack DA, James SP, et al: Seasonal affective disorder and phototherapy. Annals NY Acad Sci 453:261-269, 1985

59. Hellekson CJ, Kline JA, Rosenthal NE: Phototherapy for seasonal affective disorder. Am J Psychiatry 143:1035-1037, 1986

60. Wirz-Justice A, Bucheli C, Schmid AC, et al: A dose relationship in bright white light treatment of seasonal depression (letter), Am J Psychiatry 143:932-933, 1986

61. Lewy AJ, Wehr TA, Goodwin FK, et al: Light suppresses melatonin secretion in humans. Science 210:1267-1269, 1980

62. Crzeisler CA, Allan JA, Strogatz SH, et al: Bright light resets the human circadian pacemaker independent of the timing of the sleep-wake cycle. Science 233:667-671, 1986

63. Lewy AJ: Effects of light on melatonin secretion and the circadian system of man, in Circadian Rhythms in Psychiatry. Edited by Wehr TA, Goodwin FK. Pacific Grove, CA, Boxwood Press, 1983

64. Lewy AJ, Sack RL, Miller S: Antidepressant and circadian phase-shifting effects of light. Science 235:352-354, 1987

65. Gwinner, E: Annual rhythms: Perspective, in Handbook of Behavioral Neurobiology. Edited by Aschoff J, New York, Plenum Press, 4:381-389, 1981

66. Gwinner, E: Circannual systems, in Handbook of Behavioral Neurobiology. Edited by Aschoff J, New York, Plenum Press, 4:391-411, 1981 
67. Hoffman, K: Photoperiodism in vertebrates, in Handbook of Behavioral Neurobiology. Edited by Aschoff J, New York, Plenum Press, 4:449-473, 1981

68. Aschoff, J: Annual rhythms in man, in Handbook of Behavioral Neurobiology. Edited by Aschoff J, New York, Plenum Press, 4:475-487, 1981

69. Rosenthal NE, Sack DA, Carpenter CJ, et al: Antidepressant effects of light in seasonal affective disorder. Am J Psychiatry 142:163-170, 1985

70. Jacobsen FM, Wehr TA, Skwerer RA, et al: Morning versus midday phototherapy of seasonal affective disorder. Am J Psychiatry 144:1301-1305, 1987

71. Wirz-Justice A, Bucheli C, Graw P, et al: How much light is antidepressant? Psychiatry Research 17:75-77, 1986

72. Voudouris NJ, Peck CL, Coleman G: Conditioned placebo responses. Journal of Personality and Social Psychology 48:47-53, 1985

73. Evans, FJ: Expectancy, therapeutic instructions, and the placebo response, in Placebo: Theory, Research, and Mechanisms. Edited by White L, Tursky B, Schwartz GE, New York, Guilford Press, 215-228, 1985

74. Siegel, S: Drug-anticipatory responses in animals, in Placebo: Theory, Research, and Mechanisms. Edited by White L, Tursky B, Schwartz GE, New York, Guilford Press, 288-305, 1985

75. Shapiro AK, Morris LA: The placebo effect in medical and psychological therapies, in The Handbook of Psychotherapy and Behavior Change: An Empirical Analysis, 2nd Edition. Edited by Garfield SL, Bergin AE. New York, Wiley and Son, 1978

76. Winokur G, Zimmerman M, Cadoret R: 'Cause the Bible tells me so. Arch Gen Psych 45:683-684, 1988

77. Spitzer RL, Cantwell DP: The DSM-III classification of the psychiatric disorders of infancy, childhood, and adolescence. J Amer Acad of Child Psychiatry 19:356-370, 1980 